\title{
Strategic Action Agenda for Preservation in Research Libraries
}

\author{
Report and Recommendations to the Scholarly Communication Steering Committee, the Public \\ Policies Affecting Research Libraries Steering Committee, and the Research, Teaching and \\ Learning Steering Committee
}

\section{Editor statement}

We have included this Strategic Action Agenda for Preservation, because it is increasingly important that libraries and information services (LIS) keep a strong position in this strategic LIS activity, often referred to as repositories. This integral document allows also an insight in the important and time consuming labour provided by volunteers/peers of our profession.

Johan van Halm

E-mail: JohanvanHalm@cs.com

\section{Prepared by the Future of Preservation in ARL Libraries Workshop Planning Task Force}

Task Force Members:

Sarah Michalak (Chair), University of North Carolina at Chapel Hill Libraries

Julie Arnott, University Libraries of Notre Dame

Joseph J. Branin, The Ohio State University

Nancy E. Gwinn, Smithsonian Institution Libraries

Andrew Hart, University of North Carolina at Chapel Hill Libraries

Thomas Teper, University of Illinois at Urbana-Champaign Library

\section{Staff liaison:}

Karla Hahn, Director, Office of Scholarly Communication, Association of Research Libraries

\section{Introduction}

The members of the Association of Research Libraries (ARL) hold a stunning array of cultural and information resources, diverse in both content and form. In building these collections, ARL libraries strive to enable current scholarship and anticipate the needs of future generations of scholars. With this long view of the world of learning, research libraries hold preservation as a fundamental role and responsibility. Grand in concept, preservation is accomplished through practical decisions and technical processes that reflect not only the ideals of academia but also the changing realities of current technology, financial resources, and the information marketplace. 
Recognizing and anticipating the magnitude of changes underway in the information landscape, ARL created the Task Force on the Future of Preservation in ARL Libraries to engage research library leaders, stakeholders, and technical experts to define critical challenges in preservation today and propose an action agenda to meet them. The recommendations described in this report draw heavily on the ideas of thirty colleagues with diverse perspectives on preservation who attended a meeting convened by the Task Force at the University of North Carolina at Chapel Hill, September 27-29, 2006. Participants in this meeting articulated changes in the nature of what must be preserved, highlighted the need for many institutions to work collaboratively to effect preservation, and explored the intersections of preservation and related library practices.

\section{Changing nature of library collections brings new preservation responsibilities}

The nature of library collections is changing and with change come new challenges for preservation. Paper-based books and manuscripts have been the mainstay of scholarly communications and library collections for hundreds of years. But in less than two decades digital information has become a mainstay of research in all disciplines. Web documents, moving images, sound recordings, and data sets are an increasing part of every day life and communication for much of the world. Rapidly these media are forming a substantial part of the cultural record. Formats - particularly digital formats - just emerging or once considered specialized areas of collecting are growing more important and mainstream for scholarship. The contemporary research library must collect and preserve a greater variety of formats than ever before, each with particular characteristics, vulnerabilities, and needs for care.

Historically the act of collecting has been the first and most significant step in preservation. The challenge, however, of caring for what we collect has become more complex in the contemporary era. Few, if any, libraries can in good faith promise the same longevity of access for an analog magnetic tape, a color photograph, or a digital file that was possible with printed books, serials, and documents. But research libraries have risen to the challenge before. The poor quality of ground wood paper with acidic sizing was apparent to readers in the nineteenth century, long before there was a scientific understanding and a viable mass-produced alternative. Fortunately, libraries collected millions of books during what has become known as the brittle books era, and incrementally developed strategies - better storage, conservation, de-acidification, reformatting - to preserve at least some of this important record. As in the past, scholarship depends on collecting content based on intellectual value, not media permanence. However, the continued work of developing preservation strategies in research libraries requires a new level of intensity to succeed in an information landscape that is more complex and less stable than ever.

\section{Libraries must make choices}

Some of the most difficult decisions in preservation processes, whether dealing with analog or digital media, are not technical but rather selection judgments about what object, or part of an object, is worth preserving. Questions familiar to conservators and selectors for microfilm projects are every bit as relevant and at least as hard to answer for librarians engaged in reformatting unstable non-print media or the migration of electronic resources. What aspects of an information object convey its essential meaning? Does a given preservation action change the user's confidence in authenticity? Is there intrinsic value to a particular artifact? For example, consider the comparison between the sound of a vinyl phonograph record and a compact disc of the same music. For whom does this difference matter and why? Is it sufficient to maintain searchability for the various fields of a given database or is it also important to 
retain the look and feel of its original search interface? Increasingly works will exist in both tangible and digital form. When is there enough cultural significance or possible evidentiary value in the tangible artifacts to retain and preserve them indefinitely?

Collecting and preserving digital materials presents us with new, daunting challenges. One is the pace of deterioration. Most digital storage media, as well as analog audio and video recording tapes, are expected at best to last a matter of decades with some instances of loss in just a few years. By comparison, the aging process for acidic paper seems mercifully slow, opening a long window of opportunity for improved storage, deacidification, conservation, and reformatting before materials become hopelessly brittle and discolored. The faster rate of physical deterioration for modern storage media is matched, if not over-shadowed, by the pace of technological change for the devices, programs, and skills necessary for access. Some have suggested the lack of durable storage media is a moot issue when physical degradation is out-paced by cycles of hardware and software obsolescence. However, this is not the case for research libraries where acquisition may occur many years after publication and scholarly uses often differ in scope and longevity from the intended purpose of any given resource. We must find practical methods of recovering content from a wide variety of deteriorating media and continue to migrate restored content through ongoing cycles of obsolescence. Collections of analog video and audio recordings pose the greatest problems currently, but the growing imperative to preserve born digital works in addition presents even more issues of media deterioration.

\section{New approaches for traditional collections}

Two new developments are likely to profoundly affect the management and preservation of large print collections in the future. Over the last two decades research libraries have been constructing high-density shelving facilities for infrequently-used or high risk collections. These facilities, if designed and operated properly, offer cool storage with excellent humidity control and state-of-the-art systems for security and fire suppression, making them in many cases much better preservation environments than open stack, central campus libraries. Some storage facilities have been built by consortia that have recognized not only the economy of scale in a joint building project but also the potential for cooperative collection development. The preservation implications for shared collections include a reduction in duplicated effort for conservation and the chance to identify and make formal commitments to preserve complete exemplars of print works now accessed primarily in digitized form.

The relationship between retrospective print resources and their electronic manifestations is becoming a more significant issue. Mass digitization of library collections appears on the immediate horizon with Google, the Open Content Alliance, Microsoft and individual libraries moving forward quickly. How will these digital collections be preserved? What collections fall outside the scope of these mass digitization projects? And what will happen to the print items once they are digitized?

\section{Acting on the commitment to preservation}

The Task Force believes that these and other questions regarding the future of preservation will be answered in an iterative fashion through practice and research. The issues the Task Force identified and considered reflect an emerging understanding of the needs of a new era for collections and preservation. They often parallel a list of preservation needs recognized in recent planning done by the Council on Library and Information Resources, CLIR. That list included a need for a national strategy, consideration 
of the multi-format nature of 21 st century collections, and new needs for training, advocacy, infrastructure, and funding. As strategies addressing these needs emerge, the following recommendations position ARL to align its activities with other national leaders.

The ARL membership, however, has specific concerns as well and the recommendations and strategies below outline actions that support the special responsibility for preservation activity held by the membership. There is a widening spectrum of needs in preservation that can only be met through a sustained and multi-faceted approach. ARL libraries are not all consistent in their level of commitment to preservation, and Task Force members believe that libraries should be held more accountable for their preservation investments. Each research library has a core of preservation responsibilities, some that can be met only locally but others that increasingly can be met through cooperative strategies. If we are to have enduring access to scholarship, we must invest in maintaining strong preservation programs with trained and effective preservation staff who can develop viable management strategies and apply material and information science solutions.

\section{Recommendations}

\section{Affirm the commitment to the preservation mission expected of research libraries}

In May of 2002, ARL issued a statement on behalf of the member libraries reaffirming their preservation commitment. The statement is included as Appendix C. The Task Force believes it is important for ARL and its member libraries to maintain their commitment to this preservation mission.

\section{Strategies:}

Reissue the 2002 statement "reaffirming [its] commitment to preservation as one of the fundamental responsibilities of the research library community. ${ }^{1}$ " The statement should be updated to emphasize even more strongly that understanding of and adopting methods for preservation of digital content is urgent and a shared responsibility.

\section{Define recommended guidelines for minimal levels of preservation activity in ARL libraries}

While preservation activities take many forms, ARL should articulate expectations for its members. Especially as library collections embrace new formats and preservation programs embrace new approaches and seek new priorities, it is important for ARL to indicate what a research library's preservation program should include and provide assistance to members in assessing their programs.

\section{Strategies:}

\section{ARL should:}

a. conduct a preliminary general survey to describe the current range of preservation activities using both qualitative and quantitative measures.

The most strategic action in addressing concerns about member engagement is to gather data to provide a contemporary picture of preservation programs in ARL member libraries.

\footnotetext{
${ }^{1}$ The statement is available at http://www.arl.org/preserv/responsibility.html.
} 
b. develop recommendations on the kinds of data ARL should collect on an ongoing basis and minimum expectations for preservation activities among research libraries. Recommendations will be grounded in data from the ARL Preservation Statistic, and data from other recent preservation surveys.

Discussions at the workshop repeatedly indicated that it is time for ARL to redesign the data it collects on member preservation activities. The current ARL Preservation Statistics are more and more inadequate as the nature of library collections changes rapidly and members grapple with rapidly diversifying, and often cooperative, approaches to preservation. Existing data support traditional preservation functions but are increasingly out of sync with emerging functions.

c. develop a description of a basic preservation program for ARL member libraries.

Data from the member survey should be used in conjunction with existing data sources to create a statement describing an appropriate set of preservation activities and investments for research libraries. The statement should provide guidance to members in assessing their programs.

$d$. develop a self-assessment instrument for members to use in assessing their preservation programs.

Research libraries must take responsibility for the preservation of new kinds of collections and for works in many formats. As library collections broaden to include datasets, for instance, the range of preservation activities in which a research library engages also grows. In setting shared expectations, member libraries need tools to help measure progress and guide planning. The proposed program of self-assessment is not an end in itself but should be implemented in a manner that promotes program development and community participation. In addition to addressing minimum expectations, the assessment instrument should be broad enough also to assist members in developing more ambitious programs and identifying opportunities for making exemplary contributions.

e. ensure that preservation statistics are among the required statistics collected to define and profile member libraries.

It is growing more difficult for member libraries to quantify their preservation activities. In addition, preservation activities in a digital age are more and more often cooperative activities. Acknowledging the difficulty at present in characterizing members' programs, a qualitative approach to describing preservation activities is appropriate. Moreover, functions that are so fundamental to the identity and mission of the research library should be reflected in any library profile that is developed, including qualifications for membership.

\section{Support the library community's ability to provide stewardship for their collections}

While preservation continues to require concerted investment and management of locally housed and maintained resources, in a digital world locality is less important and preservation demands exceed those individual libraries can meet. Increased creation and use of digital surrogates changes demand for print materials and the economies of wholesale duplication shift. It is more and more evident that much preservation work can only be done effectively and efficiently through coordinated activity. Decisions about preserving local collections need to be made with an understanding of the decisions other libraries are making. As preservation activities are shifting to reflect efforts to promote and support preservation, ARL needs to take a community-wide perspective in its efforts to promote and support preservation. 


\section{Strategies:}

ARL should:

a. promote collaborative or outsourcing strategies for addressing preservation challenges,

For many formats preservation can be carried out most efficiently if libraries are not limited to local activities and in-house services. Shared preservation services are increasingly valuable and their development should be supported and promoted. Initiatives such as Europe's PRESTO project ${ }^{2}$ have shown that a production facility approach to preservation activities can take advantage of economies of scale. Increased efficiency means more libraries can preserve more content while adhering to preservation standards. The Library of Congress National Audio-Visual Conservation Center at Culpepper, Virginia is developing similar approaches. Although these efforts focus on audiovisual materials, similar processes could be developed for a wide range of highly technical preservation challenges including many digital preservation needs.

b. encourage and support partnerships to create shared collections and ensure that such efforts include an explicit preservation component (for instance, ARL could seek a unique contribution in advancing projects like the North American Storage Trust ${ }^{3}$ ).

Broad duplication of collected works has been a common preservation strategy, one that has complemented access needs in the past. As access modes for many works in member collections change and storage costs increase, more coordinated management of duplication is needed.

c. encourage the development of external funding for member libraries and/or other organizations to support existing centers of excellence in individual ARL libraries. Goals should include, broadening services to peer libraries, enhancing roles in preservation research, and providing specialized training and field experience.

Another consequence of the broadening of library collections and the shared responsibility for preservation is the increasing need for centers of expertise. Since it is not feasible for any single institution to develop comprehensive expertise in all preservation technologies, distributed concentration of expertise is needed. This is beginning to happen already, and ARL should seek opportunities to support and encourage emerging centers of excellence.

d. encourage the development of in-service training curricula and strategies that include multiformat presentations.

Preservation staff need to expand their expertise with new formats and new kinds of collections, like datasets. Training opportunities to support new skills must be encouraged, recognizing that it may not be ARL's role to lead in their development.

e. seek partnerships that create opportunities for preservation staff to develop their skills and their leadership capabilities. Likely partners include I-schools, member libraries, and ALA/ALCTS/PARS.

f. CLIR and the Library of Congress are developing advocacy around preservation of new formats. ARL is well positioned to contribute at a high level in emphasizing clear, consistent messages that can be communicated to faculty, administrators, legislators, and funding agencies.

\footnotetext{
${ }^{2}$ More information on the PRESTO project is available at http://presto.joanneum.ac.at/index.asp.

${ }^{3}$ The North American Storage Trust is a project to develop tools for libraries to use in making decisions about which print titles they need to maintain locally and to make and share commitments to maintain various titles.
} 
As the preservation challenge grows in quantity and complexity the need to educate stakeholders outside of the library community is increasingly pressing. It has been demonstrated often that when members of other communities understand the challenge they become committed to helping.

g. ARL's member libraries should support ongoing research on preservation methodologies, monitoring developments and where possible participating in studies.

The need for action in this arena is not limited to ARL. Member libraries are important leaders and partners in efforts to develop new methodologies to address new needs. The broadening range of formats libraries collect plus the rise of formats dependent on mediating technologies requires ongoing research into existing and emerging preservation technologies. The NDIIPP ${ }^{4}$ effort represents a significant investment in research into digital preservation. ARL can encourage member participation in NDIIPP and promote awareness of the outcomes of the program's research efforts.

\section{Promote public policy that enables and enhances preservation efforts}

Copyright law governs a range of preservation activities and ARL's ongoing engagement in this field of public policy offers tremendous benefits for preservation work. Most recently, activities seeking to ease handling of orphan works and to contribute to the ongoing review of Section 108 of the Copyright Statute have important implications for preservation.

\section{Strategies:}

ARL should:

a. continue the commitment to reducing legal and other barriers to access, use and preservation of the research results of publicly funded research projects and publications,

b. create a statement encouraging application of the fair use doctrine and Section 108 for creating preservation surrogates of a broader array of media,

Workshop discussions suggest that there is considerable uncertainty regarding the restrictions copyright places on various preservation activities. A statement affirming the importance of the exercise of all of the rights granted under copyright law and the ability of libraries to undertake preservation of materials in all formats in accordance with copyright law would encourage a more proactive approach to preserving works not in the public domain.

c. pursue a partnership with ALA to develop education and discussion within the preservation community of applications of fair use and section 108,

An education program addressing copyright in the preservation context would increase understanding of copyright law and its application in traditional and developing preservation activities among those charged with preservation management. ALA/ALCTS/PARS should share interest in developing this type of training.

d. seek partnerships to develop more efficient ways for libraries to determine copyright status for individual items in large-scale digital reformatting projects.

\footnotetext{
${ }^{4}$ Further information on NDIIPP (The National Digital Information Infrastructure and Preservation Program) is available at http://www.digitalpreservation.gov/index.html.
} 
A substantial challenge facing preservation reformatting is the difficulty of determining the copyright status for many works in library collections. Many mass digitization programs are taking a conservative approach in treating works that are not obviously in the public domain. The development of a mechanism to share the results of research on the status of individual works would provide substantial benefits.

\section{Engage in emerging issues around preservation of electronic resources}

Workshop participants and task force members agree that preservation of materials existing in digital formats is currently the greatest preservation challenge facing research libraries. All of the recommendations address digital preservation issues in one way or another, but the Task Force wishes to suggest additional strategies for this issue. ARL has already done notable work in this arena with its statement "Recognizing Digitization as a Preservation Reformatting Method" CLIR study, "E-Journal Archiving Metes and Bounds: A Survey of the Landscape" by Kenney et al. For the foreseeable future it will be important for ARL to retain a leadership role and encourage its members to assume leadership in this arena of preservation activity.

\section{Strategies:}

ARL should:

a. approve the Scholarly Communication Steering Committee's proposal for endorsing the recommendations of the report by Kenney et al. on e-journal preservation,

$b$. continue efforts to promote the development of digital repositories and promote the development of capabilities that allow libraries individually and collectively to fulfill their stewardship role for the digital resources collection,

ARL has a history of leadership in promoting digital repository development, and it is important to maintain involvement with the services and technologies of repositories. That involvement should extend beyond access to include the development of effective preservation strategies and functions.

c. inform members of the state of the art as the arena of digital preservation evolves.

Information on preservation issues reaches members through a variety of channels. It will be important to continue to monitor developments in arenas such as NDIIPP and identify important issues and developments for members.

\section{Resources and assessment}

Two of the recommended strategies would best be supported by the recruitment of Visiting Program Officers. Workshop attendees urged that a contemporary picture of preservation programs in member libraries be developed. A VPO would survey the membership regarding the full range of support for preservation activities applied to all formats. ${ }^{6}$ As preservation of digital formats has become an increasingly pressing issue and as more collaborative approaches to preservation develop, new ways of describ-

\footnotetext{
${ }^{5}$ The statement is available at http://www.arl.org/preserv/digit_final.html.

${ }^{6}$ The VPO would be a leader from the preservation community who would work with ARL staff under the auspices of the Scholarly Communication Steering Committee. A similar model was used for ARL's current Copyright Education Initiative and the Public Policies in Research Libraries Steering Committee.
} 
ing and gathering data on preservation activities are sorely needed. This VPO position is described in Appendix D.

In setting shared expectations for research libraries, member libraries need tools to help in assessing their own programs to measure progress and guide their planning. The task force believes that the best way to accomplish this is to work with a second Visiting Program Officer (described in Appendix E). This work could be sequenced to occur in conjunction with the membership survey or to follow that work.

\section{Conclusion}

Re-commitment, training, advocacy, research and development of new technologies and processes, measurement and assessment, collaboration and immediate engagement in the preservation of digital collections are the recommended strategies for the coming years. These strategies build on a past of successful engagement of the entire research library community but especially on the work of preservation practitioners and sponsors over half a century. Looking ahead there is much work to do - in fact for some important emerging formats work is just beginning. Library collections are diversifying beyond their traditional boundaries to include new media, such as e-books, and a broader range of the products of research, for instance datasets. If we were to choose one message from the Workshop on the Future of Preservation participants to the ARL community, it is that preserving the cultural record is as important as collecting it.

\section{Appendix A: Task Force Charge}

\section{The Future of Preservation in ARL Libraries Workshop Planning Task Force}

Prepared by the Scholarly Communication Steering Committee

Sponsored by the Scholarly Communication Steering Committee, the Public Policies Affecting Research Libraries Steering Committee, and the Research, Teaching, \& Learning Steering Committee

November 1, 2005

Background: Research libraries are entering a new era of preservation challenges. The documents that research libraries collect are in a wide range of formats, from text, to images to magnetic and digital multimedia. Special collections are achieving a new prominence. Technology provides novel tools for tackling preservation issues, but also presents new problems. It is time for ARL and the preservation community to think hard about how best to invest resources and select priorities in facing these challenges.

Charge: The Task Force is charged to design an invitational workshop with the goal of defining the critical challenges now facing research libraries in ensuring enduring access to research collections, particularly those in digital formats. The workshop aims to engage research library directors and those charged with preservation of library collections both traditional and digital in consideration of the highest priority opportunities for action.

The workshop should produce an action agenda emphasizing highest priority areas for attention. The agenda should suggest appropriate roles for research libraries, ARL, PARS (a section of ALCTS), CLIR and other key stakeholders. 
The Task Force is asked to design the workshop to engage leaders and visionaries from a range of stakeholders from the research library community including, library directors, preservationists working with a variety of formats, special collections librarians managing multi-format collections, and managers of digital collections. Invitees should also include those who can assist in engaging appropriate partners and stakeholders such as national libraries and archives, PARS, and CLIR.

The workshop is envisioned as a one-day event. The desired outcome for the workshop is a list of the highest priority preservation issues that research libraries should address, with identification of the recommended roles and responsibilities of individual research libraries and ARL as well as other organizations such as PARS, CLIR, and others as appropriate. The Scholarly Communication Steering Committee will work with the Task Force in reviewing their workshop design and invitee list.

Following the workshop, the Task Force is asked to bring the recommendations from the workshop along with their own assessment of the outcomes to all three sponsoring Steering Committees and the Board and should make recommendations regarding the broader dissemination of the workshop results.

Composition: The task force will be composed of five members, including the chair. Three members, including the chair, are ARL directors, and two should be other librarians from member libraries who have preservation expertise.

Timeframe: The task force is encouraged to offer the workshop in Spring or Summer of 2006, to present a preliminary report at the October 2006 Membership Meeting, and to create a final report by the end of December 2006.

Resources: The task force will need a moderate level of ARL staff support for the project. Staff will work with task force to assist in the design and implementation of the workshop.

\section{Appendix B: Participants in the Future of Preservation in ARL Libraries Invitational Meeting}

\section{Participants}

Whitney Baker, Conservator, University of Kansas

Neil Beagrie, British Library/JISC Partnership Manager, The British Library (Speaker)

Wesley Boomgaarden, Preservation Officer, The Ohio State University Libraries

Connie Brooks, Preservation Consultant, Council on Library and Information Resources

Charlotte Brown, University Archivist, University of California at Los Angeles Library

Sherry Byrne, Preservation Librarian, University of Chicago Library

Margaret Byrnes, Head, Preservation \& Collection Management Section, National Library of Medicine Nancy Cline, Roy E. Larsen Librarian of Harvard College, Harvard University

Patricia Cruse, Director, Digital Preservation Program, California Digital Library

Robin Dale, Program Officer, Research Libraries Group

Carol Pitts Diedrichs, Dean of Libraries, William T. Young Endowed Chair, University of Kentucky Libraries

Pierre Gamache, Director General of the Care of Collection Branch, Library and Archives Canada

Janet Gertz, Director for Preservation, Columbia University Libraries

Anne Kenney, Associate University Librarian, Instruction, Research and Information Services, Cornell University Library 
Kris Kiesling, Director of Archives and Special Collections, University of Minnesota Libraries

Thomas Leonard, University Librarian, University of California, Berkeley Library

Clifford Lynch, Executive Director, Coalition for Networked Information

Carol Mandel, Dean of Libraries, New York University Libraries

Sian Meikle, Digital Services Librarian, University of Toronto

Susan Perry, Interim President, CLIR and Senior Advisor, The Andrew W. Mellon Foundation, Council on Library and Information Resources

Roberta Pilette, Head of Preservation, Yale University Libraries

Bernard Reilly, President, Center for Research Libraries

Mark Sandler, Director, Center for Library Initiatives, Committee on Institutional Cooperation

Roger Schonfeld, Manager, Research, Ithaka

Dianne van der Reyden, Director of Preservation, Library of Congress

Donald Waters, Program Officer for Scholarly Communications, Andrew W. Mellon Foundation

\section{ARL Future of Preservation in ARL Libraries Workshop Task Force}

Sarah Michalak (Chair), University Librarian and Associate Provost for Libraries, University of North Carolina at Chapel Hill Libraries

Julie Arnott, Head of Preservation, University Libraries of Notre Dame

Joseph J. Branin, Director of Libraries, The Ohio State University

Nancy Gwinn, Director, Smithsonian Institution Libraries

Andrew Hart, Preservation Librarian, University of North Carolina at Chapel Hill Libraries

DeEtta Jones, Consultant to the Task Force

Thomas Teper, Head of Preservation and Assistant Professor, John "Bud" Velde Endowed Professorship, University of Illinois at Urbana-Champaign Library

\section{ARL Staff}

Karla Hahn, Director, Office of Scholarly Communication, Association of Research Libraries

\section{Appendix C: The Responsibility of Research Libraries for Preservation}

\section{May 22, 2002}

The members of the Association of Research Libraries reaffirm their commitment to preservation as one of the fundamental responsibilities of the research library community. A research library collection is a key capital asset of the parent institution. Through individual and cooperative efforts, a principal goal of research libraries is to preserve the record of knowledge from the past and present represented in the collection and to carry out this basic responsibility into the future. To invest in protection of this asset is a wise and responsible act to insure against loss.

Preserving the record of knowledge is a fundamental, but also an expensive and complex, undertaking for research libraries. Currently members of the Association for Research Libraries spend collectively over 100 million dollars annually on preservation activities. In a world where the production of information far exceeds any single institution's capability to manage it completely, research libraries must 
carefully and collaboratively select and actively preserve the most informative and representative records of past intellectual achievement in order to ensure the continuing growth of knowledge.

The universe of recorded knowledge includes all subjects and a vast and expanding array of physical formats, ranging from incised stone tablets to ink on parchment and paper, to photographs and film, to analog sound and moving picture recordings, to complex digital objects. The form in which information is produced and delivered will continue to change and evolve over time. Information content is intertwined with its physical, recorded form; sometimes this content is separable from its physical form, and sometimes it is not. Because of the sheer magnitude and variety of information produced, research libraries must make wise and economical choices among a spectrum of options from conserving an artifact in its original manifestation to preserving only its informational content in an alternative format that best facilitates its continued use.

Research libraries must act strategically, cooperatively, and in a multi-faceted way to get the most out of their preservation efforts. These efforts include the full complement of preventive and corrective measures. Among them will be establishing environmental conditions and handling procedures that promote the longevity of materials; providing repair, conservation, commercial binding, and deacidification solutions that best fit collection needs; using analog and digital methods to reformat materials that are beyond repair or conservation for content preservation and/or greater accessibility; constructing effective disaster preparedness programs and responses; implementing standards and best practices for permanent archiving of content in digital form; developing collaborative programs to preserve endangered materials with important artifactual value; and educating library staff and users so that they understand and can assist in the preservation enterprise.

Approved 5/22/02 by the ARL Preservation of Research Library Materials Committee.

Approved 5/24/02 by the ARL Board of Directors.

\section{Appendix D: Description of Position for Visiting Program Officer on Measuring Preservation Activities in ARL Libraries}

\section{Background}

In reviewing discussions from the workshop, it became evident that there are significant gaps in our knowledge of current preservation activities in ARL member libraries. We know that preservation activities are shifting and evolving rapidly but our ability to describe and measure members' engagement in new approaches to preservation is limited. The current ARL Preservation Statistics are more and more inadequate as the nature of library collections changes rapidly and members grapple with rapidly diversifying, and often cooperative, approaches to preservation.

Some important studies have gathered data that can supplement our preservation statistics, but the breadth of these efforts is largely limited to covering more institutions beyond the ARL membership rather than substantially enhancing the kinds of data that are collected. As recently as 2002, CLIR worked with ARL to survey preservation in research libraries ${ }^{7}$, but the findings rely heavily on ARL's existing preservation statistics and predate developments such as third party e-journal archiving, digital repositories, and NDIIPP. The Heritage Health Index, published in 2005, collects a range of important

\footnotetext{
${ }^{7}$ See Anne R. Kenney and Deirdre C. Stam. (2002) "The State of Preservation Programs in American College and Research Libraries: Building a Common Understanding and Action Agenda.” CLIR. 56 pp. available at http://www.clir.org/pubs/ reports/pub111/pub111.pdf.
} 
data on library preservation activities but does not report data for research libraries separately and gathered only modest data on digital preservation activities. This makes the data of limited value in enhancing the information already collected through the preservation statistics.

Nevertheless, it will be important to consider the results of these studies when designing a new member survey and in developing recommendations. It will be important to define the range of preservation activity broadly to include a full range of formats for tangible works but also preservation of digital works and activities developing outside of the milieu of tangible assets. The survey should also consider members' contributions to cooperative preservation efforts.

\section{Charge}

The VPO would consider broadly the qualitative and quantitative data needed to describe the full range of preservation activities supported and being developed by member libraries and provide an analysis based on data collected through an ad hoc member survey, existing statistics, and other approaches. The data analysis should include comparisons with earlier surveys done by CLIR and the Heritage Health Index.

\section{Activities}

- Design and implement an ad hoc member survey.

- Analyze survey data and develop a report on the survey findings and analysis.

- Based on the survey data and in conjunction with data from the ARL Preservation Statistics, the CLIR study of the state of preservation, and the Heritage Health Index results develop recommendations on:

$\circ$ the minimum preservation activity levels expected of member libraries.

o whether to continue the Preservation Statistics program.

- appropriate qualitative descriptors that would be appropriate for ARL member profiles.

- In developing a final report and recommendations, lead a full-day meeting with a small group of preservation leaders (for instance the members of this task force and two or three others).

\section{Deliverables}

- A report that will be published by ARL.

- A presentation to the membership on the survey findings.

- Organization of a meeting with a group of preservation leaders to review the draft report findings and recommendations.

\section{Time commitment}

It is estimated that this work will require an eight month commitment at $25 \%$ time for the VPO. 


\section{Appendix E: Description of Visiting Program Officer on Self-assessment for Preservation Programs}

\section{Background}

ARL has a history of supporting self-assessment of preservation activities in research libraries. In the early 1990's a self-study manual and a series of program planning resource guides were developed and continue to be widely used. Over the last decade, the range of formats collected by research libraries has grown with materials in formats other than print assuming greater importance. Cooperative approaches to preservation such as third party archiving and the growth of digital repositories are developing rapidly. It is time again for ARL to support the development of a new generation of assessment tools.

\section{Charge}

The VPO will create a self-assessment instrument calibrated to the needs of contemporary collection environment and reflecting state-of-the-art practice both for in-house and cooperative preservation activities. The assessment tool should cover the full range of formats and address changing priorities and ideas about what aspects of collected works need to be preserved.

Data from the ad hoc member survey and the recommendations for member libraries should inform the design of the self-assessment.

The VPO should consider how best to disseminate the instrument and support members' selfassessment activities. Possible approaches could include design of SPEC studies, development of a new set of resource guides for twenty-first century program planning, or the creation of consulting services.

\section{Activities}

- Design a self-assessment instrument for 21 st century preservation programs in research libraries.

- Promote the instrument and its use by ARL member libraries.

- Consider further activities such as workshops, resource guides, SPEC studies, consulting services to support self-assessment.

\section{Deliverables}

- A web-delivered self-assessment tool.

- A presentation to the membership on the self-assessment.

- An article on self-assessment of research library preservation programs for the ARL Bimonthly Report. 